Review

\title{
The Role of 5G Technologies in a Smart City: The Case for Intelligent Transportation System
}

\author{
Ali Gohar * ${ }^{(D)}$ and Gianfranco Nencioni
}

check for

updates

Citation: Gohar, A.; Nencioni, G. The Role of 5G Technologies in a Smart City: The Case for Intelligent Transportation System. Sustainability 2021, 13, 5188. https://doi.org/ $10.3390 /$ su13095188

Academic Editors: G G Md Nawaz Ali, Md. Noor-A-Rahim, Mohammad Omar Khyam and Xuejun Li

Received: 26 March 2021

Accepted: 29 April 2021

Published: 6 May 2021

Publisher's Note: MDPI stays neutral with regard to jurisdictional claims in published maps and institutional affiliations.

Copyright: (c) 2021 by the authors. Licensee MDPI, Basel, Switzerland. This article is an open access article distributed under the terms and conditions of the Creative Commons Attribution (CC BY) license (https:// creativecommons.org/licenses/by/ $4.0 /)$.
Department of Electrical Engineering and Computer Science, University of Stavanger, 4021 Stavanger, Norway; gianfranco.nencioni@uis.no

* Correspondence: ali.gohar@uis.no

\begin{abstract}
A smart city is an urban area that collects data using various electronic methods and sensors. Smart cities rely on Information and Communication Technologies (ICT) and aim to improve the quality of services by managing public resources and focusing on comfort, maintenance, and sustainability. The fifth generation (5G) of wireless mobile communication enables a new kind of communication network to connect everyone and everything. 5G will profoundly impact economies and societies as it will provide the necessary communication infrastructure required by various smart city applications. Intelligent Transporting System (ITS) is one of the many smart city applications that can be realized via $5 \mathrm{G}$ technology. The paper aims to discuss the impact and implications of 5G on ITS from various dimensions. Before this, the paper presents an overview of the technological context and the economic benefits of the $5 \mathrm{G}$ and how key vertical industries will be affected in a smart city, i.e., energy, healthcare, manufacturing, entertainment, and automotive and public transport. Afterward, 5G for ITS is introduced in more detail.
\end{abstract}

Keywords: 5G applications; autonomous vehicle; Internet of Things; intelligent transportation system; smart cities; sustainability; V2X; wireless communication

\section{Introduction}

Telecommunication utilizes various methods and mediums, which can be wireless and wired, to support information communication at a distance between two or more nodes that form a network. The telecommunications revolution, particularly wireless mobile communication, has made significant progress as it has evolved through various generations, as shown in Figure 1. This evolution is characterized by the technical implementation of a specific standard, including new techniques and features that differentiate it from the previous generation [1].

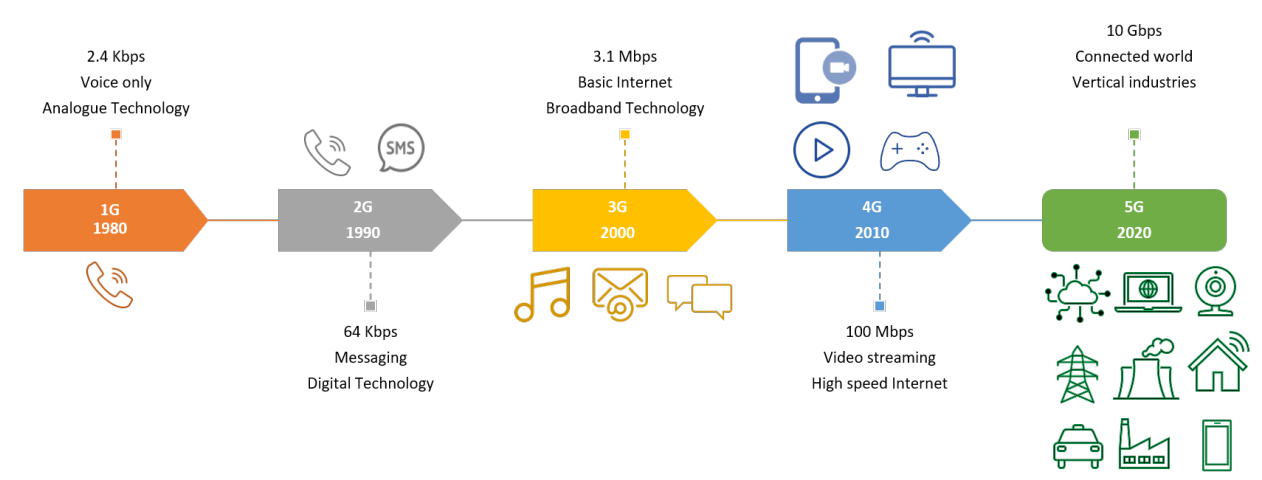

Figure 1. The evolution of mobile communications. 


\subsection{From $1 G$ to $4 G$}

The first generation (1G) of mobile communication was introduced in the early 1980s, and it only supported voice calls and used analog radio signals. In $1 G$, the Frequency Division Multiple Access (FDMA) scheme was used, which divides the frequency into channels and assigns each channel to only one user at a time. The $1 G$ mobile network had poor voice quality, did not support roaming, and calls were not encrypted. On a $1 \mathrm{G}$ network, the maximum data transmission speed was around $2.4 \mathrm{Kbps}$. The second generation $(2 \mathrm{G})$ was introduced in the 1990s and used digital radio signals with improved voice quality and increased data rate capacity. The Global System for Mobile Communications (GSM) was a digital standard for $2 \mathrm{G}$ and supported data services such as Short Message Service (SMS) and Multimedia Message Service (MMS). Time Division Multiple Access (TDMA) and Code Division Multiple Access (CDMA) were the two schemes used in 2G. TDMA divides signals into time slots and assigns each user a unique code generated by a CDMA. $2 \mathrm{G}$ had data transfer rates that ranged from 30 to $35 \mathrm{Kbps}$. A later version of $2 \mathrm{G}$, known as Enhanced Data Rates for GSM Evolution (EDGE), was theoretically capable of data transmission speeds of up to $1 \mathrm{Mbps}$.

The third generation (3G) appeared in the late 2000s. The International Telecommunication Union (ITU) defined $3 \mathrm{G}$ requirements as part of the International Mobile Telephone 2000 (IMT-2000) project, also known as the Universal Mobile Telecommunications System (UMTS) because it allows for global roaming. The primary distinction between 2G and 3G was that $3 G$ used packet switching rather than circuit switching, which allowed access to Internet applications and basic multimedia streaming. The $3 \mathrm{G}$ initially supports a data transfer rate of $200 \mathrm{Kbps}$, but subsequent iterations support up to $3.1 \mathrm{Mbps}$. The ITU published requirements for IMT-Advanced, also known as fourth generation (4G) mobile communication, in 2008. Long-Term Evolution (LTE) became the industry standard after 4G was introduced in the early 2010s. 4G's key technologies were Orthogonal Frequency Division Multiplexing (OFDM) and Multiple Input Multiple Output (MIMO). OFDM divides a digital signal into many narrowband channels with varying frequencies. Furthermore, the main difference between $3 \mathrm{G}$ and $4 \mathrm{G}$ was that $4 \mathrm{G}$ was entirely based on Internet Protocol (IP). 4G enabled High-Definition (HD) video streaming and high-speed Internet access with data rates of up to $100 \mathrm{Mbps}$ [2].

With more than 7.95 billion connections, mobile networks have become the primary and most widely used communications technology [3]. However, mobile networks are used by more than just people; they are also used by a variety of other devices collectively known as the Internet of Things (IoT). Billions of IoTs are expected to be globally connected over the next decade, creating a new distributed ecosystem named the Internet of Everything (IoE) [4]. With the large-scale interconnection of people and things, there will be a tremendous growth of data traffic, which puts a strain on the current generation of wireless mobile communication. Therefore, fueled by the unprecedented growth in the number of connected devices, mobile data traffic, and the limitations of $4 \mathrm{G}$ technologies, industry and academia are focusing their efforts on defining the specifications for the fifth generation (5G) of wireless mobile communication.

More than 1000 cities in the world have a population of over 500,000 people, and nearly 55 percent of the world's population lives in cities, with this figure expected to rise to 68 percent by 2050 [5,6]. With the increase in the relocation of people to urban space, new challenges arise and require cities to manage these challenges. This has resulted in global initiatives to make cities more sustainable with the help of technological advances [7]. The goal of these initiatives is to make cities smarter, which gave rise to the Smart City concept. Smart cities aim to improve service quality by managing public resources, emphasizing comfort, maintenance, and sustainability. The Internet of Things (IoT) is a communication paradigm that allows everyday objects to communicate with one another via the Internet. The IoT paradigm finds application in many different domains, such as manufacturing, healthcare, energy and utility management, automotive and public transport, and many others. The IoT will promote several applications to provide new services to citizens, 
companies, and public administrations. Furthermore, applying the IoT paradigm to an urban context is of particular interest because it addresses the need of many national governments to adopt solutions based on Information and Communication Technologies (ICT) in public affairs management, thereby realizing the so-called Smart City concept [8,9]. According to IoT Analytics, the top three IoT projects in 2018 were smart cities, connected industry, and connected buildings [10]. Moreover, the smart city global market is projected to grow from $\$ 410.8$ billion in 2020 to $\$ 820.7$ billion by 2025 , at a compound annual growth rate of 14.8 percent [11].

\subsection{The $5 G$}

The 5G network is supported by technological advances that will transform the core of mobile communication networks. 5G will enable a wide range of application scenarios by introducing a completely new network architecture. To make immersive solutions possible and ubiquitous, new technologies such as Artificial Intelligence (AI) and Multi-access Edge Computing (MEC), as well as the concept of network slicing and softwarization technologies such as Software-Defined Networking (SDN) and Network Function Virtualization (NFV), will play a critical role. MEC is a key enabler for applications requiring near-real-time performance and decision making. MEC allows data to be processed close to its point of origin, reducing network latency. SDN is a networking paradigm that allows networks to be programmed, whereas NFV uses virtualization technology to implement different types of hardware-based network equipment as software instances [12].

Compared to 4G, 5G will support 10 to 100 times higher data rates and the number of connected devices. Moreover, 5G will provide nearly 100 percent availability and geographical coverage with improved security and privacy. Furthermore, 5G will consume ten times less energy while extending the battery life for devices by ten times [13-16] 5G technology implementation focuses on key technologies such as new radio access, massive Multiple Input Multiple Output (MIMO), heterogeneous ultra-densification, channel coding and decoding, and Millimeter Wave (mmWave) [17]. Further details on the technologies used by $5 \mathrm{G}$ are out of the scope of the paper. It is expected that the $5 \mathrm{G}$ will provide $\$ 12.3$ trillion in goods and services across all industries in 2035 and will support up to 22 million jobs in the $5 \mathrm{G}$ value chain [18].

5G lays the foundation for building a productive industry, smart technology, and innovative ways of communicating. In addition, $5 \mathrm{G}$ will act as the communication network to support the IoT infrastructure required by various smart city vertical industries. $5 \mathrm{G}$ will support a diverse set of use cases requirements across different vertical industries, including energy, health care, manufacturing, media and entertainment, automotive, and public transport, to name a few. The concept of network slicing has been developed to address the diverse service requirements of vertical industries.

A slice is a collection of logically customized network functions that support the communication service requirements of specific use cases or business models. Network slices are categorized into different types according to the abstraction of characteristics of the services they facilitate, as shown in Figure 2. The 3rd Generation Partnership Project (3GPP) has defined four network slice types as follow [19]:

- $\quad$ Enhanced Mobile Broadband (eMBB): This slice type has higher data rates and better coverage requirements.

- Massive Internet of Things (mIoT): This slice type generally has a large number of devices in a small area. mIoT applications include low-cost and low-energy devices that communicate small data packets such as IoT in smart cities. Other industry groups use the term Massive Machine Type Communications (mMTC) to classify this group of services $[20,21]$.

- Ultra-Reliable and Low Latency Communication (uRLLC): This slice type is also known as critical communications. This generally supports devices that have stringent latency and reliability requirements. 
- Vehicle-to-Everything (V2X) communication: This slice type supports communication between vehicle and the environment.

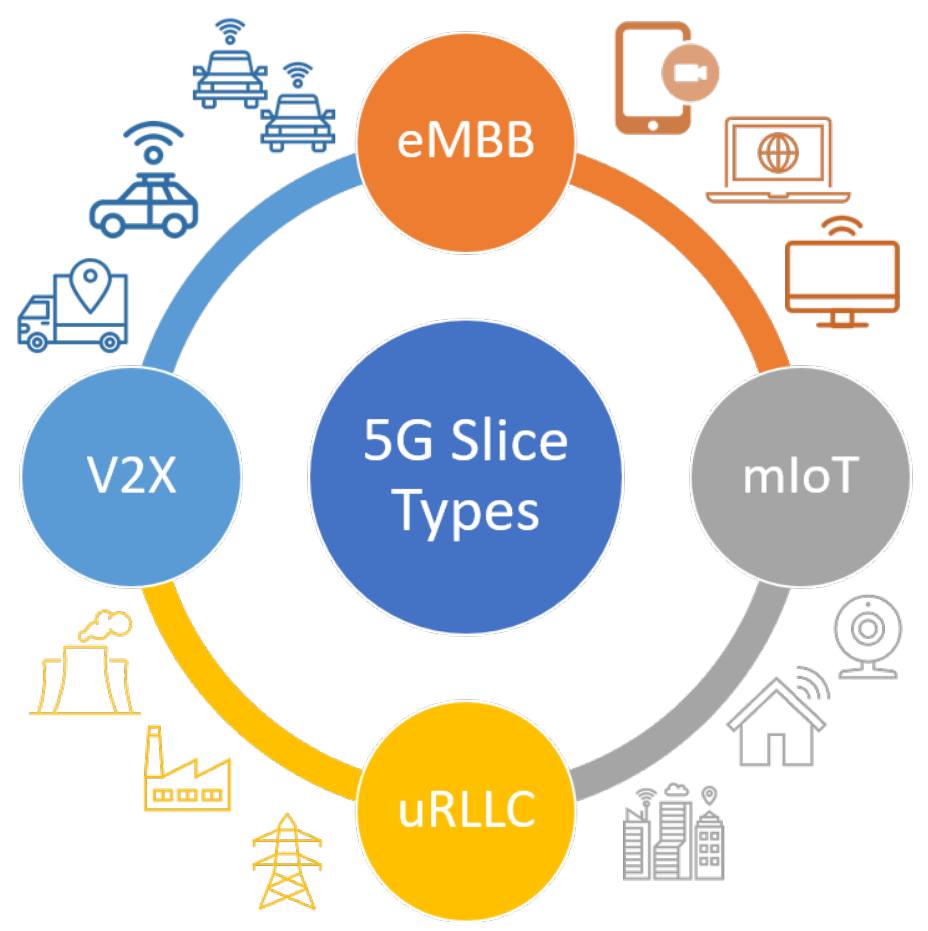

Figure 2. Slice types supported by 5G.

These network slice types present a wide range of technical challenges as they identify performance requirements, including power efficiency, high reliability, spectrum efficiency, channel robustness, low latency, lower cost, high energy performance, cooperative networking, co-existence, etc.

\subsection{1. eMBB}

This network slice type is a natural evolution to existing $4 \mathrm{G}$ networks that will provide faster data rates and better user experiences to densely populated metropolitan centers. Use cases of eMBB are expected to support a connection density of up to one million connections per square kilometer with support for downlink speeds approaching $1 \mathrm{Gbps}$ indoors and $300 \mathrm{Mbps}$ outdoors and a data traffic volume of at least 1 Tbps per square kilometer. Moreover, the support for high mobility up to $500 \mathrm{~km} / \mathrm{h}$ in high-speed trains and up to $1000 \mathrm{~km} / \mathrm{h}$ in airplanes, with enhanced user experience.

\subsection{2. mIoT}

This network slice type enables mass sensing, monitoring, and metering that typically require small data volumes but have strict cost and energy constraints. Use cases of mIoT are expected to support 30,000 devices per cell (most cells will contain smaller devices), low devise complexity, and a battery life of 10 years with an AA battery.

\subsection{3. uRLLC}

uRLLC is arguably the most innovative $5 \mathrm{G}$ feature. It can enable a wide range of applications, some of which are currently unknown. uRLLC has substantial restrictions on the delivery time of a packet, which is $1 \mathrm{~ms}$, and the packet loss ratio of $10^{5}$. Compliance with these requirements is necessary for the automation of production, the creation of intelligent transport systems, and the support of virtual or augmented reality and the tactile internet. 


\subsubsection{V2X}

Vehicular communication is a critical technology in the intelligent transportation system to connect vehicles, roadside units, and pedestrians. V2X use cases are expected to support a maximum communication latency between 3 to $500 \mathrm{~ms}$, a data rate between 10 to $1000 \mathrm{Mbps}$ having reliability between 90 to 99.999 percent, and a communication range between 50 to $1000 \mathrm{~m}$.

\subsection{Related Works, Contributions, and Structure of the Paper}

ICT frameworks support various smart city functions by connecting a diverse set of dedicated networks of sensors, mobile devices, communication gateways, and data centers, as well as power plants, hospitals, schools, libraries, water supply networks, waste management, transportation systems, law enforcement, and other community services. As the IoT becomes a primary mode of communication in smart cities, its applications present diverse engineering and research challenges. To address these challenges, new architectures, protocols, and services are required. 5G will represent a key turning point in the evolution of smart cities because it will enable high-speed connectivity, low latency, longer battery life, and the ability to handle a massive number of connections, all of which will create new potential services and modify existing ones.

The paper [22] discusses the role of 5G communication and IoT in a smart city while taking into consideration transportation. However, it fails to demonstrate the economic impact of 5G technology in various vertical industries and the requirements for the 5G enabled transport. The paper [23] elaborates on the technologies and presents a summary of vertical industries for the smart cities. However, several other important aspects are missing related to the role of mobile communication in a smart city along with the economic impact of each vertical industry enabled by 5G technology. The paper [24] briefly discusses the impact of $5 \mathrm{G}$ on the evolution of industry digitization and intelligent automation. It highlights the key features of 5G networks and the role of 5G technology in various vertical industries. However, it fails to take into consider the smart city context and the economic impact of 5G technology on various smart city vertical industries. The most relevant study to this review in terms of $5 \mathrm{G}$ vehicular communication is conducted by the authors of [25], who extensively review the 5G communication technology for vehicular networks with a focus on 5G-V2X communications. They elaborate on the 5G-V2X standardization, architecture, use cases, and its key enablers such as network-slicing and edge-computing. However, the authors did not discuss different implications of the 5G enabled transport while leaving out the context of the smart city and the economic impact. The paper [26] discusses the components that make up the smart city, the technological enablers in terms of architectures, networking technologies, and algorithms deployed in smart city systems. Moreover, it also presents a review of the various applications in a smart city. However, it does not address the state-of-the-art on the 5G technology and how it can act as an enabler and accelerator to the smart city development along with its economic impact. In [27], authors provide an overview of the role of $5 \mathrm{G}$ New Radio (NR) for vehicle-to-everything communication by introducing the technological components of 5G NR and how 5G NR can support various $\mathrm{V} 2 \mathrm{X}$ use cases for cooperative and autonomous driving.

The rise of the automotive industry in the late 1920s disrupted almost every industry. For more than a century, the affordability of vehicles fueled economic growth across a wide range of industries. However, technological advancement is revolutionizing transportation in the form of autonomous vehicles. The rise of autonomous vehicles will result in one of history's most rapid, profound, and far-reaching transformations [28]. 5G is an enabler and an accelerator to the social benefits of connected, automated, shared, and electrified vehicles and will indeed become central to the transformation of the autonomous vehicle industry. The purpose of this research is to conduct a literature review that is dominated by consultant narratives and promises and to investigate the implications of the 5G enabled intelligent transportation system through various dimensions. Table 1 summarizes the different topics addressed by this paper. The table presents of these topic is addressed 
by the presented related works. The table highlights that, as the best knowledge of the authors, this is the first work that explores the implications for 5G-enabled Intelligent Transportation Systems.

Table 1. Summary of related papers.

\begin{tabular}{|c|c|c|c|c|}
\hline Reference & 5G Overview & $\begin{array}{c}5 G \text { for Smart City } \\
\text { Verticals }\end{array}$ & $\begin{array}{c}5 \mathrm{G} \text { for } \\
\text { Transportation }\end{array}$ & $\begin{array}{c}\text { Implications for } \\
\text { 5G-Enabled } \\
\text { Transportation }\end{array}$ \\
\hline Guevara, L. et al. [22] & $\checkmark$ & & $\checkmark$ & \\
\hline Sánchez-Corcuera, R. et al. [23] & & $\checkmark$ & & \\
\hline Attaran, M. [24] & & $\checkmark$ & & \\
\hline Hakeem, S.A.A. et al. [25] & & & $\checkmark$ & \\
\hline Syed, A.S. et al. [26] & $\checkmark$ & $\checkmark$ & $\checkmark$ & \\
\hline Bagheri, H. et al. [27] & & $\checkmark$ & $\checkmark$ & \\
\hline This paper & $\checkmark$ & $\checkmark$ & $\checkmark$ & $\checkmark$ \\
\hline
\end{tabular}

This paper is structured as follows:

- In this section, we have highlighted the role of mobile communication technology and IoT in realizing a smart city concept.

- In Section 2 we discuss how 5G will act as an enabler and accelerator of innovation for various smart city vertical industries such as energy, health care, manufacturing, entertainment, and transport. Furthermore, in this section, we investigate the economic impact of $5 \mathrm{G}$ technology on each vertical industry before moving on to the next section, which focuses on one vertical industry in particular.

- $\quad$ Successively, we focus on the impact of 5G on transportation:

- Section 3, focuses on the transport as a vertical industry. Here we motivate the need to have an intelligent transportation system and how $5 \mathrm{G}$ will act as an enabler for this vertical industry. We explore the $5 \mathrm{G}$ use cases for the transportation system, their benefits and state the requirements supported by $5 \mathrm{G}$.

- In Section 4, we elaborate the implications of the intelligent transportation system through various dimensions. Here we see how ITS will be optimized to help reduce the economic and environmental impact of transportation and new challenges and vulnerabilities related to ITS privacy and security, as well as ethical and social issues that may stymie ITS deployment.

- $\quad$ Finally, in Sections 5 and 6, we discuss and conclude the paper.

\section{2. $5 \mathrm{G}$ for the Vertical Industries in a Smart City}

The $5 \mathrm{G}$ and smart city are at the forefront of a new wave of generational transformation driven by multiple factors, including societal changes, economic challenges, and aging populations. In this section, the most significant vertical industries awaiting transformation by $5 \mathrm{G}$ technologies in an IoT-based smart city are examined, along with how $5 \mathrm{G}$ will be a principal driver of that transformation. In general, the applications of $5 \mathrm{G}$ technology in a smart city can be grouped into various dimensions as different industrial verticals, such as energy, health care, manufacturing, media and entertainment, automotive and public transportation [29]. Moreover, each vertical industry can have multiple use cases. Figure 3 highlights smart city vertical industries and their use cases. 


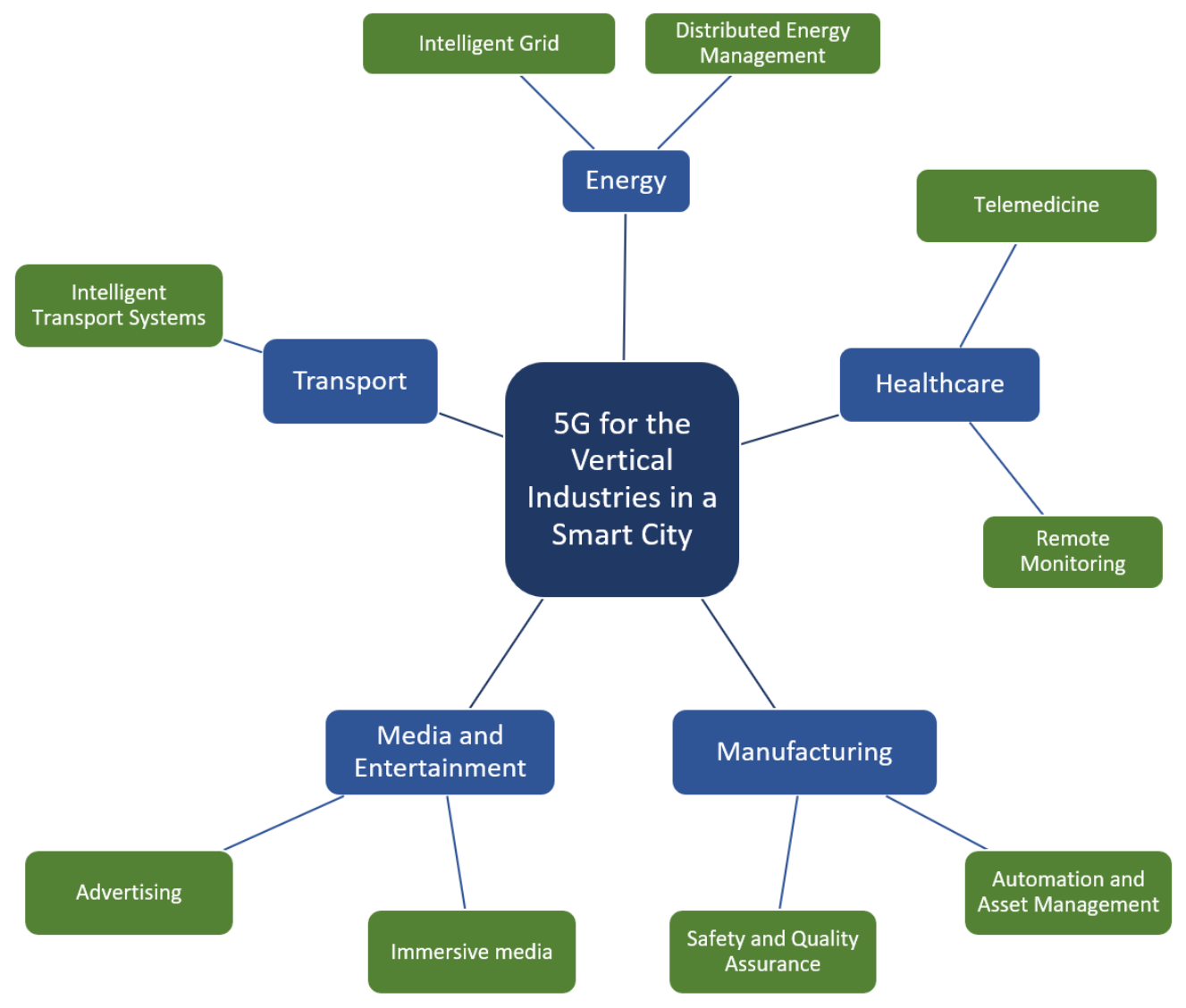

Figure 3. Smart city vertical industries and their use cases.

\subsection{Energy}

The world is changing forms of energy generation, transport, and consumption. Previously, a large central power generation plant met the demand for end-users. However, with renewable energy sources rising, we face unpredictable small-scale power plants, including solar, wind, and hydro. These small distributed power plants are numbered by thousands and are starting to replace the large traditional central power generation systems [30]. As a result, power generation and distribution networks shift from one-way power flow to two-way power flow, enabling consumers to become power producers [31].

The objective of $5 \mathrm{G}$ is to focus on the interconnection and monitoring of energy and remote power stations that generate electricity across the four components of the value chain: generation, transmission, distribution, and consumption. 5G can improve energy management, capital utilization, reduced downtime and operating costs by managing distributed energy resources, build advanced metering systems, and increase the integration of sensors into the power generation grids. The impact of $5 \mathrm{G}$ in energy will grow sales up to 1.3 percent or $€ 73.6$ billion in sales and $€ 25.1$ billion in economic benefits. Furthermore, as the impact of $5 \mathrm{G}$ spreads through the value chain, it will generate an additional $€ 38.7$ billion in GDP [32].

\subsubsection{Intelligent Grid}

Data and communication are vital to developing new intelligent grids [33]. Authors in [34] discuss communication protocols as well as the role of wireless sensor networks in smart grid applications. They propose integrating existing services into modern ICT platforms to provide new services to citizens and energy users. Moreover, the authors provide a thorough examination of wireless technologies and $5 \mathrm{G}$ communication for smart grids and future roadmaps and challenges in [35]. The intelligent grid consists of three 
main elements, i.e., distributed energy management, automated infrastructure inspection, and remote monitoring within the utility industry.

It is estimated that globally $€ 13$ billion per year will be spent by 2026 on robotics for grid monitoring [36]. Using sensors and IoT devices, 5G can enable accurate monitoring across the entire grid [37]. Remote monitoring enabled by $5 \mathrm{G}$ can help reduce operating costs of malfunctioning equipment across the entire grid by managing alarms and, in some cases, through equipment control such as pylon stability [38,39]. A digital twin is a virtual representation that serves as the real-time digital counterpart of a physical asset and is constantly updated with real-world sensor input. It enables learning, reasoning, and the ability to dynamically re-calibrate for better decision making by utilizing real-time data. The 5G-enabled digital twin technology will enable power grid operators to visualize data and monitor power grid systems for maintenance and planning. Utility companies can save 10 percent or more on operating costs by using proactive real-time monitoring enabled by $5 \mathrm{G}[32]$.

\subsubsection{Distributed Energy Management}

The management of distributed energy resources improves the production and distribution of increasingly distributed energy sources. $5 \mathrm{G}$ provides the ability to identify and react to varying energy demands in the two-way power grid by using real-time information and advanced analytics, allowing for a better response to peak demand and the prevention of potential blackouts [40]. Houses that spend about $£ 1208$ a year on gas and electricity can save $£ 145$ with intelligent $5 G$ power grids in the United Kingdom [41]. Utility companies can invest in 5G technology to create an intelligent, more responsive power grid. It is estimated that $5 \mathrm{G}$ in the utility sector will contribute up to 28 percent of 5G GDP and will help transform the current power grid into an affordable, reliable, and real-time intelligent grid.

\subsection{Healthcare}

The demand for services with ever more complex healthcare cases has increased dramatically due to longer life expectancy and the aging of baby boomers. These factors are expected to drive most of the 5 to 6 percent growth in annual healthcare spending [42].

Treatments for chronic disease drive 80 percent of the current healthcare budget across Europe. Moreover, these diseases are responsible for 86 percent of deaths, which will only rise as the population ages. According to studies, the shortages for physicians, nurses, and other healthcare workers will reach 4.1 million by 2030 [43-45]. To close this gap technology, and other scalable healthcare models will be critical.

5G could help to conceive a world that provides borderless medical care [46]. 5G will revolutionize the entire digital ecosystem capable of supporting medical research and disease diagnosis. The impact of $5 \mathrm{G}$ on healthcare is expected to driving up to $€ 77$ billion in economic output, $€ 51.2$ billion in GDP and up to 0.4 million jobs in $2026[32,47]$.

\subsubsection{Telemedicine}

Decentralization of hospitals is the most anticipated step forward with the advent of 5G. The change would bring health care closer to patient's homes with walk-in clinics, emergency care, and outpatient surgery centers. To people in rural areas with doctors working several miles away, traveling while sick can be daunting and time-consuming. However, with the introduction of telehealth, patients could receive care from their homes. Only 13 percent of doctors in the United Kingdom, for example, choose to work in a rural hospital. In addition, access to specialists frequently necessitates travel to urban centers [48]. In 2019, more than 2 percent of Europeans reported an unsatisfactory health need, with medical examinations delayed due to long wait times or travel distances, and high costs [49]. Physicians can recommend virtual consultations after a video/voice call and even apply for a prescription. The telemedicine market is expected to expand at a compound annual rate of 16.5 percent from 2017 to 2023 [50]. 


\subsubsection{Remote Monitoring}

Healthcare is facing severe cost, capacity, and skilled labor constraints, particularly in inpatient services where beds, specialists, and 24-h monitoring are scarce. Some of these constraints may be alleviated by remote patient monitoring. Various instruments can collect and analyze data on off-site patients in real-time, sending alerts when a prompt response is required. Intensive care is among the most expensive aspects of healthcare: a single day of treatment costs as much as $€ 2025$ [51]. Healthcare systems with the integration of multiple sensors enabled with $5 \mathrm{G}$ will provide continuous, reliable, and secure remote monitoring for driving better patient outcomes. Furthermore, when compared to managing satellite sites in person, this increases the flexibility to manage supply and demand better and can reduce the length of stay by up to 50 percent [52]. Early detection and intervention with 5G has the potential to improve patient outcomes significantly by delaying or completely preventing disease states from developing [53]. The suite of 5G applications, when combined, would result in significant economic benefits for healthcare, including a reduction in hospital costs of up to 16 percent due to the use of wearable remote monitoring [54]. The economic benefit of remote patient monitoring is estimated to be 30 percent of the total economic benefit of $5 \mathrm{G}$.

\subsection{Manufacturing}

Manufacturers worldwide are under extreme pressure at a time of high volatility due to shorter market and shorter product life cycles [55]. The production margins are more limited than ever, with materials increasingly varied and challenging to manufacture and aging the workforce [56,57]. The manufacturing industry had the highest injury incidents rate of any private or public sector industry in 2017, accounting for 18.7 percent [58]. Manufacturers recognize the value of digital transformations in driving productivity, but less than 30 percent of manufacturers report digital technology adoption [59]. 5G enables the building of smart factories that can use various other enabling technologies, i.e., AI that can boost productivity by 20 to 30 percent.

\subsubsection{Automation and Asset Management}

In the manufacturing process, 5G technologies have significant network capabilities to support applications that require synchronization and real-time monitoring. Factory floor automation is a broad concept that includes applications such as smart logistics with Automated Guided Vehicles (AGVs), synchronized robots, and mission-critical remote machine control. 5G will provide greater flexibility, lower costs, shorter lead times for reconfiguration, and changes to the factory floor in the manufacturing process [60].

Unplanned downtime at an automotive production facility can cost $€ 1.1$ per hour [61]. As a result, 58 percent of manufacturers expect to upgrade inspection technology in 2020, while 47 percent plan to shorten cycle times and eliminate bottlenecks by buying new equipment [62]. 5G can improve intelligent asset management by providing better asset visibility, management, and control. To reduce unplanned downtime and extend asset useful life, 5G can provide real-time asset health monitoring. In manufacturing, intelligent asset management can contribute approximately 15 percent to the 5G-enabled GDP.

\subsubsection{Safety and Quality Assurance}

Quality assurance is responsible for monitoring and responding to quality violations. Improving quality monitoring processes with 5G can improve defect detection by 90 percent along with a 50 percent increase in quality testing throughput. Furthermore, Augmented Reality (AG) and Virtual Reality (VR) can improve technicians' first-time fix rates by 20 percent to 40 percent while decreasing injuries by 5 percent to 15 percent [63]. On the floor, AR/VR can reduce downtime by 10 percent to 35 percent, scrap and rework by 15 percent to 25 percent, and assembly time by 20 percent to 50 percent [64]. In manufacturing, the productivity improvements enabled by $5 \mathrm{G}$ can contribute up to 5 percent to 5G-enabled GDP. 


\subsection{Media and Entertainment}

$5 \mathrm{G}$ is going to transform media business models. The new $5 \mathrm{G}$ network capacity and blazing speed mean annual mobile media sales will increase by $\$ 420$ billion in 2028 over the next ten years [65]. The media companies will be the first to adopt these new business models. We are looking to the future where $5 \mathrm{G}$ will add a new sensory dimension to entertainment advertising and online gaming. Traditional banner-based advertising will be transformed into moving images with integration and adaptation to an immersive experience. Various real-time dynamics will be measured by eye surveillance, biometrics, etc. In addition to the apparent advantages of improved streaming and downloading, various companies are looking beyond the fundamentals to see how 5G can change the model of entertainment. For example, for live concerts, companies are looking for ways to beam live concerts through augment reality anywhere in the world and to edit them in realtime. 5G applications are almost too numerous to be listed in the entertainment industry.

\subsubsection{Immersive Media}

5G will enable new media interactions, such as Augmented Reality (AR) and Virtual Reality (VR) content and applications, as well as cloud gaming delivered over 5G. AR, $\mathrm{VR}$, and cloud gaming are not new concepts, but $5 \mathrm{G}$ has the potential to bring them to a wider audience. The creation of volumetric 3D content and an ecosystem to manage that type of content will be required to realize this market potential fully. Augmented reality will create a new way for people to connect with media through virtual items, virtual characters, and augmented contextual information. 5G will enable augmented and virtual reality applications with total revenue of more than $\$ 140$ billion. When combined with advanced VR capabilities, 5G can support highly responsive haptic suits, introducing a new sensation dimension to media consumption such as touch and feel. Cloud gaming is on the cutting edge of 5G-driven innovation. AR games will account for more than 90 percent of 5G AR sales, totaling \$35.7 billion globally. Moreover, Mobile cloud gaming will benefit from high-resolution real-time streaming and quick response. By 2028 , total revenues for 5G mobile games, including $\mathrm{AR}$ and cloud games, are expected to exceed $\$ 100$ billion.

\subsubsection{Advertising}

The transition from traditional display advertising to social and media immersive experiences will be facilitated by 5G. The use of multimedia in the development of new $5 \mathrm{G}$ immersive formats and the resulting social integration will benefit the advertising market. Mobile advertising campaigns currently face significant challenges in terms of scale, delivery, and measurement, which $5 \mathrm{G}$ will help to address. With a global market worth $\$ 178$ billion expected by 2028 , mobile display advertising will be a significant revenue opportunity.

\subsection{Transport}

Innovation in all fields, including manufacturing, driving skills, and safety, is well known to the automotive industry. As a result, all major brands aim to build smarter and better-connected vehicles, which were expected to reach 250 million by 2020 [66].

$5 \mathrm{G}$ is an enabler and an accelerator to the social benefits of connected, automated, shared, and electrified vehicles and is likely to contribute to and will indeed become central to the development of autonomous vehicles. It is estimated that by 2035, 5G technology will deliver more than $\$ 2.4$ trillion in economic output in the broader automotive sector, which is almost 20 percent of the expected global impact of 5G [67]. Moreover, the 5G will boost revenues from the European automotive and transport sectors by up to $€ 220.5$ billion with a direct economic impact of $€ 89.5$ billion in GDP and an indirect impact of up to $€ 85.9$ billion in GDP. 
Intelligent Transport Systems

5G is committed to linking individual vehicles by developing Cooperative Intelligent Transport Systems (CITS). 5G-enabled CITS can make cities smart and help automated transport systems safer and more efficient than existing transport networks. This also helps the public transport system to deal with the key transport issues in major cities, including traffic congestion, pollution, and collisions. 5G can address these issues by enabling a truly smart transport system. With high-speed Internet access in public transports. A Connected Traffic Cloud that aggregates and analyzes real-time data from connected vehicles, infrastructure, and devices to assist in operational decision-making, better navigation, fuel and time resource efficiency, etc. Initial trials on CITS have resulted in 20 percent greater workload efficiencies, 15 percent fewer crashes, and traffic congestion [68]. Key transformations happening in the automotive industry can be summarized as follow:

- $\quad$ Automated driving.

- Road safety and traffic efficiency services.

- Intelligent navigation.

- Information society on the road.

\section{5G for Intelligent Transportation Systems}

In many developed countries, transportation accounts for 6 to 12 percent of the GDP [69]. In 2010, one billion vehicles were registered, and by 2030, this number is expected to double, putting a strain on transportation infrastructure [70]. Moreover, with a loss of approximately 1.3 million lives each year in road accidents, the fatality rate is projected to rise to 1.8 million by 2030 [71]. The concept of Intelligent Transportation Systems (ITS) is fundamental to solve transportation problems. ITS aims to provide innovative services relating to the various modes of transport and traffic management. Therefore, ITS has a tremendous potential that impacts the safety, mobility, land use, congestion, carbon emissions, energy consumption, and productivity of users [72-74].

5G has the potential to alter the ITS landscape drastically. 5G and its various slice types, such as eMBB, mIoT, uRLLC, and V2X, can enhance and improve various aspects of ITS operation and performance. To fully realize the concept of ITS, we must examine the enabling technologies and the evolution of vehicles.

\subsection{Communication for Vehicles to Everything}

The automotive industry is moving towards making vehicles more aware of their surroundings. As a result, the modern vehicle has become a sensor platform that transmits and receives data from its surroundings. Such data can be used to support advanced safety applications that reduce traffic accidents, increase traffic efficiency and improve access to emergency vehicles. However, these applications require a coordinated framework, with features that support ultra-low latency for warning signals, higher data rates for sharing sensory data between vehicles and infrastructure, high mobility, high reliability, and scalability.

Massive research has been conducted by industry and other organizations to address vehicle communication capabilities and transport infrastructures. The 3GPP defines four types of vehicular communication use cases: Vehicle-to-Vehicle (V2V), Vehicle-toInfrastructure (V2I), Vehicle-to-Pedestrian (V2P), and Vehicle-to-Network (V2N), which are all collectively referred to as V2X [75]. V2V and V2P communications are essentially between vehicles or between vehicles and vulnerable road users (for example, pedestrians, cyclists) to provide information on location, speed, and direction to avoid accidents. V2I includes direct communication between vehicles and roadside infrastructure such as Roadside Units (RSU). The RSU is used to expand the range of messages received from a vehicle by acting as a forwarding node. V2N transmission is between a vehicle and a V2X application server to support services such as streaming media for entertainment and connectivity for dynamic route management. 
With significant advances in computing and communications technologies, the automotive industry is shifting towards automated vehicles. These vehicles are equipped with on-board sensors capable of sensing their environment to navigate while performing all driving operations without human input. Such vehicles have been referred to as Autonomous Vehicles (AVs), or self-driving vehicles [76]. AV sales are expected to exceed 33 million per year by 2040, enabling new autonomous mobility in more than 26 percent of new car sales [77]. AV is a sub-part of the ITS. To determine an AV's autonomy, the Society of Automotive Engineers (SAE) International has devised an autonomy classification system based on a six-level continuum [78]. These levels range from level zero, "fully manual", to level five, "fully automated". State-of-the-art technologies have pushed the vehicle to level-three autonomy, which allows the vehicle to monitor the environment and handle emergencies such as emergency braking [79]. However, level five vehicular autonomy without any support from V2X communication is not practical [80]. Because it limits the autonomous vehicle capability to react to faster maneuvers, prevent collisions and edge cases [81-84].

\subsection{G-V2X Use Cases}

$5 \mathrm{G}$ can realize the vision of $\mathrm{AV}$ by supporting the exchange of sensor information in real-time with the massive number of connections needed to communicate with thousands of cars, roadside sensors, and other devices that may be nearby. 5G is also expected to provide high performance, reliable and robust communications, and enhanced coverage to support collision avoidance in urban and rural areas [25]. Moreover, the 5G Automotive Association (5GAA) study concludes that delivering ITS through cellular networks compared to RSU is significantly cheaper [85].

3GPP defines the performance requirements for enhanced V2X scenarios based on different vehicular automation levels $[75,86,87]$. Some of these advanced applications include vehicle platooning, remote driving, advanced driving, and extended sensors, as shown in Figure 4. Moreover, we also elaborate on each of the 3GPP enhanced V2X use cases in the following.

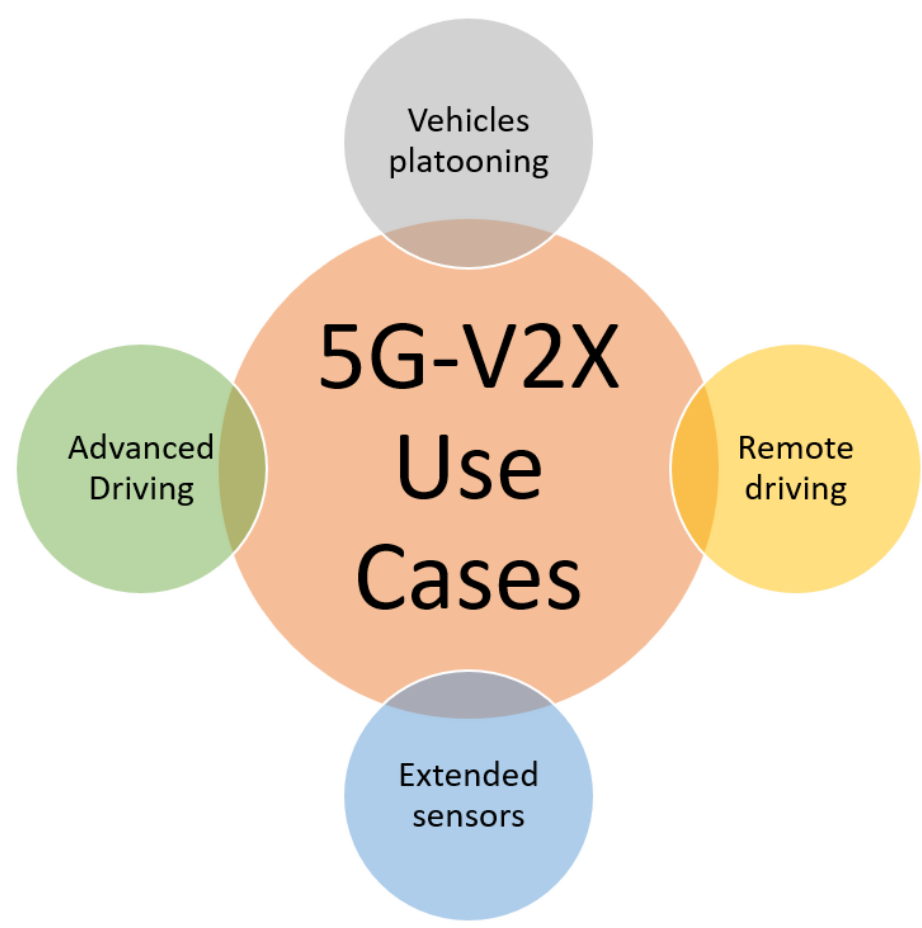

Figure 4. Enhanced V2X use cases based on different vehicular automation levels. 


\subsubsection{Vehicles Platooning}

Platooning enables vehicles to form a tightly coordinated group traveling together with significantly reduced inter-vehicle distance, thus increasing road capacity, fuel efficiency, reducing accident rates, and increasing productivity by releasing drivers to perform other tasks. All the platoon vehicles periodically exchange information with the leading vehicle and carry on platoon operations.All vehicles in a given platoon can be driven autonomously. Platooning must be supported in many aspects by reliable V2V communications:

- Joining and leaving the platoon: Allowing a vehicle to join or leave a platoon at any time while the platoon is active and supporting additional signaling to complete the joint/leave operation.

- Announcement and alerting: Allowing nearby vehicles to be aware of the platoon's formation and presence. This will facilitate the smooth operation of joining or leaving a platoon, as the vehicle wishing to join the platoon will be able to do so without disrupting the platoon.

- Management messaging: Allowing for a steady-state operation of vehicles in a platoon by exchanging management messages, including the acceleration, braking, route selection, platoon leader change, etc.

To ensure effective and safe platooning, V2V communication must support reliable and secure message exchange due to the small target inter-vehicle distance while the vehicles are traveling at relatively high speeds. The following are some of the most important V2V communication requirements for platooning:

- End-to-end communication latency is 25 milliseconds for a group of vehicles with the lowest degree of automation and 10 milliseconds for the highest degree of automation.

- Message reliability of 90 percent in a group of vehicles with the lowest degree of automation and 99.99 percent in a group of vehicles with the highest degree of automation.

- For platooning in close proximity, the relative longitudinal position accuracy of $0.5 \mathrm{~m}$ is required.

- The broadcasting rate of messages ranges from 10 to 30 messages per second.

\subsubsection{Remote Driving}

Remote driving allows a human operator or remote driver to remotely control a vehicle via $\mathrm{V} 2 \mathrm{~N}$ communication using a cloud-based application [88]. Various scenarios may use remote driving as follows:

- Edge cases can stop a vehicle on its tracks, making it unable to choose a path or approach to navigate safely. Remote driving may assist vehicles in edge cases requiring the vehicle to request a remote driver for remote-control assistance. Vehicles traveling through bad weather or near a construction site, double-parked cars preventing the vehicle from passing through the ingress/egress yellow lines, lanes blocked due to a nearby accident, and unexpected or never-before-experienced situations in which the vehicle is unable to take a safe plan of action or does not know how to proceed are examples of edge cases.

- Youth, the elderly, and others who are not licensed or capable of driving could benefit from remote driving. Moreover, moving trucks from one location to another, delivering rental cars to customers, and providing remotely driven taxi services are examples of situations where fleet owners may need to control their vehicles remotely.

- Cloud-based public transportation is best suited for services with predefined routes and stops. Remote driving has the potential to lower the cost of fully autonomous driving for specific use cases due to its lower technical requirements (e.g., fewer in-vehicle sensors and fewer computation requirements for sophisticated algorithms).

Potential V2X requirements for supporting remote driving are as follow: 
- Support for downlink data rates of up to $1 \mathrm{Mbps}$ and uplink data rates of up to $25 \mathrm{Mbps}$ (assuming two H.265/HEVC HD streams of up to $10 \mathrm{Mb} / \mathrm{s}$ each).

- An ultra-high reliability of 99.999 percent.

- An end-to-end latency of $5 \mathrm{~ms}$ between the vehicle and the V2X application server.

- Message exchange between the vehicle and V2X application server for an absolute speed of up to $250 \mathrm{~km} / \mathrm{h}$.

\subsubsection{Extended Sensors}

Extended sensors refer to a vehicle's ability to exchange raw or processed information about objects in its vicinity beyond the view of its on-board sensors. Information can be exchanged between vehicle, RSU, pedestrian, and V2X application servers. Other nearby vehicles capable of detecting these objects process them and then broadcast them to assist other nearby vehicles in providing a complete picture of the traffic environment in a given area. The sensor data that a vehicle can share ranges from a photo of a perceived object to its real-time video stream.

Sensor data from a variety of sources improves situational awareness and road safety for both vehicles and pedestrians. Extended sensors enable new features and capabilities, such as cooperative driving and the precise positioning needed for autonomous driving. Vehicles, for example, can send messages to other vehicles to alert them to Non-Line-ofSight (NLOS) situations. These are critical intersections or on-ramps, as well as weather conditions (for example, rain, fog, or snow) that limit the range of on-board sensors. The potential communication requirements between two V2X nodes to support extended sensors include:

- Maximum 100 ms end-to-end communication latency for sensor information sharing between V2X-supported applications for vehicles with the lowest degree of automation and $3 \mathrm{~ms}$ for the vehicles with the highest degree of automation.

- Maximum 50 ms end-to-end communication latency for video sharing between V2X supported applications for vehicles with the lowest degree of automation and $10 \mathrm{~ms}$ for the vehicles highest degree of automation.

- Message reliability of 99.999 percent among vehicles with the lowest degree of automation and 99.999 percent among vehicles with the highest degree of automation.

- Support for high connection density in congested areas, i.e., supporting 15,000 vehicles per mile at a congested highway intersection.

\subsubsection{Advanced Driving}

Semi or fully automated driving is possible with advanced driving. Longer intervehicle distances are allowed in this scenario. Each vehicle, or RSU, shares data from local sensors with nearby vehicles, allowing them to coordinate their driving paths. The advantages of advanced driving include safer travel, fewer collisions, and increased traffic efficiency. The following are some of the potential communication requirements between two vehicles using advanced driving communications:

- Maximum $10 \mathrm{~ms}$ end-to-end communication latency for cooperative collision avoidance between User Equipment (UE) supporting V2X application and 99.99 percent message reliability.

- Maximum $100 \mathrm{~ms}$ end-to-end communication latency for information sharing for automated driving between V2X-supported applications for vehicles with a minimum range of $700 \mathrm{~m}$ for lowest degree of automation and $360 \mathrm{~m}$ for the vehicles highest degree of automation.

Table 2 presents the summary of each of the 3GPP enhanced V2X use cases, along with their performance requirements. 
Table 2. Summary of requirements for advanced 5G-V2X use cases.

\begin{tabular}{ccccc}
\hline 5G-V2X Use Case & $\begin{array}{c}\text { Minimum- } \\
\text { Maximum } \\
\text { Range (m) }\end{array}$ & $\begin{array}{c}\text { Maximum } \\
\text { Latency (ms) }\end{array}$ & $\begin{array}{c}\text { Data Rate } \\
\text { (Mbps) }\end{array}$ & $\begin{array}{c}\text { Packet } \\
\text { Reliability (\%) }\end{array}$ \\
\hline Vehicles platooning & $80-350$ & $10-500$ & $50-65$ & $90-99.99$ \\
Remote driving & - & 5 & $1-25$ & 99.999 \\
Extended sensors & $50-1000$ & $3-100$ & $10-1000$ & $90-99.999$ \\
Advanced Driving & $360-700$ & $3-100$ & $10-50$ & $90-99.999$ \\
\hline
\end{tabular}

\section{The Implications of 5G-Enabled ITS}

The implications of $5 \mathrm{G}$ on ITS from different dimensions are discussed in this section. We first highlight sustainability and economic implications of how ITS enabled with 5G will lead to optimized transport systems that will improve transport economies and sustainability. Next, we examine the venerability of the ITS and how it creates privacy problems in terms of security and privacy. In the final analysis, we examine the ethical and social aspects of the ITS, and we discuss and explore the ethical and social challenges in implementing an ITS.

\subsection{Economic and Sustainability Implications}

In terms of sustainability, the ITS will result in optimized transportation systems reducing the waste of time by optimizing routes, lower congestion, pollution, environmental impact, and improving vehicle and driver performance [89,90].

Cars are estimated to be responsible for approximately 30 percent of carbon-dioxide emissions [91]. Automated vehicles in Germany could prevent more than 30,000 collisions or 70 percent of rear-end collisions by 2025 , or $€ 450$ million in repair and crash cost savings, as calculated by Automotive Supplier Bosch [92]. Furthermore, automated driving systems have the potential to save German commuters up to $95 \mathrm{~h}$ per year and alone save 400,000 tons of $\mathrm{CO}^{2}$ by 2025. Similarly, Bosch estimates that by 2025, automated vehicles in the United States (U.S.) each year can save 4000 lives and prevent more than 210,000 crashes. This safety improvement would translate to $\$ 3.6$ billion in repair and collision cost savings for U.S. citizens and insurance companies [92]. The U.S. National Highway Traffic Safety Administration estimates that the combined impact of V2X technologies could mitigate the severity of up to 80 percent of non-impaired multi-vehicle crashes and 70 percent of crashes involving commercial trucks [93].

Due to the static nature of traffic lights, which are preprogrammed to remain green or red for fixed intervals regardless of how much traffic flow comes from each direction, intersections are estimated to cause up to 45 percent of traffic congestion [94]. Moreover, through adaptive traffic signals, a 25 percent reduction in traffic congestion and a 30 percent reduction in idling at intersections can be realized [95]

Traffic congestion is estimated to cost 1 percent of the EU's GDP, which equals $€ 100$ billion each year [96] Traffic congestion costs in the United Kingdom alone could reach $€ 307$ billion, or $€ 2057$ per household, by 2030 [97]. Cooperative Intelligent Transport System (C-ITS) is viewed as a critical enabler of the future of automated driving by the European Commission. The long-term benefits for implementing a C-ITS are estimated to outweigh the costs by a factor of three [98].

Early tests in the Chinese Hangzhou province by Alibaba City Brain have shown that connected infrastructure results in 15 percent fewer crashes, 15 percent less traffic congestion, and 20 percent greater workload efficiencies for their smart highway project [68]. 5G-enabled transportation infrastructure is a must-have, given the addressable 166 billion annual costs of traffic delays [93].

Furthermore, the Los Angeles Transportation Agency reports that parking-seekers account for up to 30 percent of traffic in metropolitan areas [99]. This is a significant source of traffic congestion, air pollution, and environmental degradation [100]. In the U.S., an 
early V2I application that includes a signaling priority for emergency services has been tested in the city of Detroit, resulting in a 20 percent improvement in response times [101].

\subsection{Security and Privacy Implications}

The increased interest in ITS development and smart cities has created new challenges and vulnerabilities that may harm human safety [102,103]. To make the right driving decisions, AVs heavily rely on sensor data, which inevitably expands the potential threat surface and poses serious security risks [104,105]. Hacking core functions such as engine disengagement and braking systems have been demonstrated successfully $[105,106]$. Furthermore, the hackers were able to remotely control the digital systems of vehicles via the Internet, causing Chrysler to recall 1.4 million vehicles in 2015 [107]. Moreover, researchers discovered 14 vulnerabilities in the infotainment systems of several BMW models in a recent study [108]. Overall, these incidents highlight that security for vehicular systems has become essential and must be addressed with high priority [109].

To make AV secure, internal and external AV issues must be considered, along with its privacy. More than 90 percent of road accidents are attributed to human error [110]. In addition, the driver's inattention and aggressive behavior are a significant part of road accidents [111]. As a result, AV internal issues concern in-vehicle detection and warning to provide alerts or stimulation if the driver appears to be impaired. The in-vehicle systems can monitor driver vigilance, drowsiness, and fatigue [112,113]. External issues are concerned with the safety of other vehicles and pedestrians.

Finally, the last issue is related to the privacy of an AV. AVs rely on continuous data exchange and require significant processing capabilities that carry personal information of an individual's identity, behavior, and location [114]. Furthermore, there are concerns about individual privacy, such as whether individuals can be identified, access to their data, and where it is stored [115]. Furthermore, there is debate over whether data collected by AVs can be used as legal evidence [116]. The 5GAA identifies and maps the privacy requirement to control and technical requirements as follow [117]:

- Minimum disclosure: Nonexplicit identification of vehicles using temporary pseudoidentifiers.

- Conditional anonymity: Identification of misbehaving vehicles and implementing corrective actions.

- Unlinkability: Using a pseudonym for a limited time in conjunction with multiple pseudonyms on a vehicle. Furthermore, the transmission behavior should change as the pseudo identifiers change.

- Forward and backward privacy: Revoking certificates for current and future periods makes it impossible to link messages signed in previous periods.

\subsection{Ethical and Social Implications}

It is challenging to deploy AV technology immediately on public roads [82-84]. At the current level of vehicle autonomy, fatal incidents have occurred due to human negligence or machine error $[118,119]$. The legal framework for self-driving cars does not yet exist, but one based on ethics can be developed. However, ethics-based solely on numbers appears naive and incomplete; thus, rights, responsibilities, competing values, and other factors frequently enter the equation [120]. What complicates matters the most is the conflict between ethics and law, such as a sound judgment can lead to illegal driving behavior, i.e., drivers may legitimately want to go faster than the speed limit in an emergency. Furthermore, global differences in ethical programming for autonomous vehicles and moral choices for autonomous vehicles are not universal [121]. As a result, social acceptance of autonomous vehicles is a significant issue $[120,122]$.

An AV's ability to make ethically complex decisions while driving, particularly before a collision, is the most controversial issue [123]. In this case, the machine must decide whether it is preferable to save an adult or a child or whether it is preferable to veer towards a motorcyclist wearing a helmet rather than one who is not because they are more 
likely to survive a crash [124]. People may begin to engage in risky behaviors to be safe if algorithms target those who are less at risk, such as cycling without a helmet [116]. Few people would buy an AV if they prioritized others' lives over the lives of its driver and passengers. However, if the sole purpose is to protect the driver, AV may collide with children or light vehicles rather than other cars or walls [125]. Similarly, people can abuse AV knowing that they can safely arrive at home, encouraging them to consume more alcohol because they will not have to worry about drunk driving [126].

As AV becomes widespread, the question of whether non-autonomous vehicles should be banned for safety reasons arises [127]. AV will be subjected to extremes of heat and cold, as well as vibration and moisture. A glitch in the AV control system could make it more harmful [128]. As a result, it is currently unclear who is liable if an AV crashes [123]. The European Commission has issued 20 recommendations to researchers, policymakers, manufacturers, and deployers for the safe and responsible use of autonomous vehicles, taking into account ethical and legal challenges such as dilemma situations and shared moral values [121].

Taxi drivers, parking attendants, car mechanics, traffic officers, and possibly bus and freight drivers are among those who will lose their jobs if self-driving vehicles become feasible $[129,130]$. However, according to a study, a customer service representative can replace the human driver role who can assist passengers, provide information, and ensure their safety [129]. Furthermore, with AV taking over driving jobs, human drivers will be able to spend their time doing higher-value work, resulting in even more progress [131]. Uber recognized that many of its drivers might lose their jobs due to AV, so they developed computer science, engineering, and maintenance programs for those interested in upskilling and transitioning careers [132]. Finally, the AV may deprive humans of one of the primary pleasures of driving a vehicle [133].

\section{Discussion}

Each of the first four generations introduced a new level of connectivity. This trend is expected to continue with $5 \mathrm{G}$, which will enable new technological advancements and innovation opportunities. In comparison to previous generations of mobile communication, $5 \mathrm{G}$ is faster, more responsive, uses less power, and can connect more devices. However, as with any new technology, there are numerous challenges and disadvantages that must be considered in order for it to grow significantly and rapidly.

Consumers and businesses are becoming increasingly concerned about security and privacy as devices become more connected. Government regulations, global standardization, technological maturity, and costs are the major challenges. Various businesses, according to Ericsson, are facing challenges such as data security and privacy, a lack of standards, and end-to-end implementation [134]. Because 5G will use mmWaves, which are known for having a short-range, more vulnerable hardware will be added to increase the range of $5 \mathrm{G}$ connectivity. To realize the full potential of 5G networking, technological and business model innovation, as well as investment in new capabilities and talent, will be required. The majority of vertical industries will be required to equip their teams and infrastructure with $5 \mathrm{G}$ capable hardware in order to reap the full interconnected benefits of 5G. As a result, additional training and costs will be required.

The primary contribution of $5 \mathrm{G}$ is typically discussed as improving vertical industry operational effectiveness. On a social level, however, there is a need to connect various vertical industry use-cases to the creation of social value in the context of the UN Sustainable Development Goals (SDGs). There is a need to educate the masses on the benefits of the 5G technology. Because the lack of understanding of the technology by the masses creates a barrier to its implementation [135]. For example, the 5G coronavirus conspiracy theory resulted in the burning of 77 mobile towers in the United Kingdom [136]. In the context of the UN SDGs, the general public can be educated on how 5G mobile communication technology is viewed as a provider of social value across eleven key areas, the most important of which are contributing to good health and well-being, improving 
infrastructure, promoting sustainable industrialization, and fostering innovation. 5G can add social value by encouraging responsible consumption, enabling sustainable cities and communities, and boosting economic growth [137].

ITS is critical for increasing social productivity, enhancing sustainability, and serving as a foundation for economic growth. 5G provides the connectivity required for ITS to function. However, it paves the way for future challenges such as creating a legal framework for ITS, industrial policy, and applications, to name a few. Intelligent transportation systems require sound industrial policies to ensure that their structure, size, layout, and technological level meet national economic and social development needs. As a result, to address the legal framework for ITS, policy, technology, and fundamental law for intelligent transportation should be established.

Moreover, 5G-based ITS can enable the interconnection of various modes of transportation and the development of a unified traffic network and integrated hub coordination. There is a need to develop ICT solutions and algorithms that can maintain reasonable levels of traffic flow autonomously and allow the convergence of various modes of transportation, such as highways, metros, railways, airports, and waterways. Furthermore, there are challenges related to security and privacy for which new techniques and solutions are required.

The mass marketing of $5 \mathrm{G}$ is still in its early stages. The researchers, on the other hand, are looking into the requirements of the sixth generation (6G) of mobile communications. Building on the success of $5 \mathrm{G}, 6 \mathrm{G}$ is expected to have a significant impact on mobile communication by integrating traditional terrestrial mobile networks with emerging space, aerial and underwater networks to provide anytime anywhere access to mobile communication. Furthermore, $6 \mathrm{G}$ will explore new communication mechanisms while remaining unconstrained by existing network paradigms or technology.

\section{Conclusions}

The 5G technologies are emerging on the markets and have not yet been fully implemented. Therefore, we can expect the implementation of various 5G applications to improve the existing services and provide new and more innovative services in years to come. However, the four main paradigms that are to be advocated with 5G technologies are the concepts of IoT, Smart Cities, ITS, and Industry 4.0.

5G based on high bandwidth, and ultra-low-latency capabilities will fuel an engine of economic growth and innovation across all industries, driven by creating new industries sub-industries, cost optimization, and product and service quality improvements. This manuscript reviews the impact of 5G technology use cases and how different vertical industries in a smart city will transform or innovate. Moreover, we specifically highlight how vehicular communication can lead us to realize an ITS and its implications in a smart city. We explore the implications of an ITS from various dimensions, i.e., economic, sustainability, security, privacy, ethics and social.

The transformative impact of 5G, which is based on high bandwidth, IoT, and ultralow latency capabilities, will fuel an engine of economic growth and innovation across all industries, fueled by the creation of new industries sub-industries, cost optimization, and product and service quality improvements. However, it will also pave the way for new challenges that are not only technical in nature, but also social and ethical in nature.

Author Contributions: Conceptualization, A.G. and G.N.; formal analysis, A.G.; investigation, A.G.; writing-original draft preparation, A.G.; writing-review and editing, A.G. and G.N.; visualization, A.G.; supervision, G.N. Both authors have read and agreed to the published version of the manuscript.

Funding: The APC was funded by the University of Stavanger via the Stavanger University Library.

Conflicts of Interest: The authors declare no conflict of interest. 


\section{References}

1. Lucky, R.W.; Eisenberg, J. Renewing U.S. Telecommunications Research; The National Academies Press: Washington, DC, USA, 2006.

2. Penttinen, J.T.J. Positioning of 5G. 5G Explained: Security and Deployment of Advanced Mobile Communications; Wiley Telecom: Hoboken, NJ, USA, 2019; pp. 47-70. [CrossRef]

3. Digital 2020: Global Digital Overview. Available online: https://datareportal.com/reports/digital-2020-global-digital-overview (accessed on 3 May 2021).

4. Miraz, M.H.; Ali, M.; Excell, P.S.; Picking, R. A review on Internet of Things (IoT), Internet of Everything (IoE) and Internet of Nano Things (IoNT). In Proceedings of the 2015 Internet Technologies and Applications (ITA), Wrexham, UK, 8-11 September 2015; pp. 219-224. [CrossRef]

5. United Nations. World Urbanization Prospects; United Nations: New York, NY, USA, 2018.

6. United Nations. World Urbanization Prospects: The 2018 Revision; United Nations: New York, NY, USA, 2019.

7. Joss, S.; Sengers, F.; Schraven, D.; Caprotti, F.; Dayot, Y. The Smart City as Global Discourse: Storylines and Critical Junctures across 27 Cities. J. Urban Technol. 2019, 26, 3-34. [CrossRef]

8. Zanella, A.; Bui, N.; Castellani, A.; Vangelista, L.; Zorzi, M. Internet of Things for Smart Cities. IEEE Internet Things J. 2014, 1, 22-32. [CrossRef]

9. Yan, J.; Liu, J.; Tseng, F.M. An evaluation system based on the self-organizing system framework of smart cities: A case study of smart transportation systems in China. Technol. Forecast. Soc. Chang. 2020, 153, 119371. [CrossRef]

10. IoT-Analytics. The Top 10 IoT Segments in 2018-Based on 1600 Real IoT Projects; Technical Report; IoT-Analytics: Hamburg, Germany, 2018. Available online: https://iot-analytics.com/top-10-iot-segments-2018-real-iot-projects (accessed on 3 May 2021).

11. Wood, L. Global Smart Cities Market Report 2020-2025: Analysis \& Forecasts of Smart Transportation, Smart Buildings, Smart Utilities, Smart Citizen Services. 2020. Available online: https://www.businesswire.com/news/home/20201008005413/en/ Global-Smart-Cities-Market-Report-2020-2025-Analysis-Forecasts-of-Smart-Transportation-Smart-Buildings-Smart-UtilitiesSmart-Citizen-Services---ResearchAndMarkets.com (accessed on 3 May 2021).

12. Nencioni, G.; Garroppo, R.G.; Gonzalez, A.J.; Helvik, B.E.; Procissi, G. Orchestration and Control in Software-Defined 5G Networks: Research Challenges. Wirel. Commun. Mob. Comput. 2018, 2018, 1-18. [CrossRef]

13. Monserrat, J.F.; Mange, G.; Braun, V.; Tullberg, H.; Zimmermann, G.; Bulakci, O. METIS research advances towards the 5G mobile and wireless system definition. EURASIP J. Wirel. Commun. Netw. 2015, 2015. [CrossRef]

14. Al-Falahy, N.; Alani, O.Y. Technologies for 5G Networks: Challenges and Opportunities. IT Prof. 2017, 19, 12-20. [CrossRef]

15. Klaine, P.V.; Imran, M.A.; Onireti, O.; Souza, R.D. A Survey of Machine Learning Techniques Applied to Self-Organizing Cellular Networks. IEEE Commun. Surv. Tutor. 2017, 19, 2392-2431. [CrossRef]

16. Fourati, H.; Maaloul, R.; Chaari, L. A survey of 5G network systems: Challenges and machine learning approaches. Int. J. Mach. Learn. Cybern. 2020, 12, 385-431. [CrossRef]

17. Agiwal, M.; Roy, A.; Saxena, N. Next Generation 5G Wireless Networks: A Comprehensive Survey. IEEE Commun. Surv. Tutor. 2016, 18, 1617-1655. [CrossRef]

18. PSB Research-5G Economy Global Public Survey Report Commissioned by Qualcomm. 2019. Available online: https: //www.qualcomm.com/media/documents/files/psb-public-survey-report.pdf (accessed on 3 May 2021).

19. 3GPP-Technical Specification Group Services and System Aspects; System Architecture for the 5G System (5GS); Stage 2 (Release 16). 2020. Available online: https://portal.3gpp.org/desktopmodules/Specifications/SpecificationDetails.aspx?specificationId= 3144 (accessed on 3 May 2021).

20. ITU-IMT Vision-Framework and Overall Objectives of the Future Development of IMT for 2020 and beyond. 2015. Available online: https:/ / www.itu.int/rec/R-REC-M.2083 (accessed on 3 May 2021).

21. Popovski, P.; Mange, G.; Gozalvez-Serrano, D.; Rosowski, T.; Zimmermann, G.; Agyapong, P.; Fallgren, M.; Höglund, A.; Queseth, O.; Tullberg, H.; et al. D6.6 Final Report on the METIS 5G System Concept and Technology Roadmap. 2014. Available online: https:/ / riunet.upv.es/handle/10251/76765 (accessed on 3 May 2021).

22. Guevara, L.; Auat Cheein, F. The Role of 5G Technologies: Challenges in Smart Cities and Intelligent Transportation Systems. Sustainability 2020, 12, 6469. [CrossRef]

23. Sánchez-Corcuera, R.; Nuñez-Marcos, A.; Sesma-Solance, J.; Bilbao-Jayo, A.; Mulero, R.; Zulaika, U.; Azkune, G.; Almeida, A. Smart cities survey: Technologies, application domains and challenges for the cities of the future. Int. J. Distrib. Sens. Netw. 2019, 15, 155014771985398. [CrossRef]

24. Attaran, M. The impact of $5 \mathrm{G}$ on the evolution of intelligent automation and industry digitization. J. Ambient. Intell. Humaniz. Comput. 2021. [CrossRef]

25. Abdel Hakeem, S.A.; Hady, A.A.; Kim, H. 5G-V2X: Standardization, architecture, use cases, network-slicing, and edge-computing. Wirel. Netw. 2020, 26, 6015-6041. [CrossRef]

26. Syed, A.S.; Sierra-Sosa, D.; Kumar, A.; Elmaghraby, A. IoT in Smart Cities: A Survey of Technologies, Practices and Challenges. Smart Cities 2021, 4, 429-475. [CrossRef]

27. Bagheri, H.; Noor-A-Rahim, M.; Liu, Z.; Lee, H.; Pesch, D.; Moessner, K.; Xiao, P. 5G NR-V2X: Toward Connected and Cooperative Autonomous Driving. IEEE Commun. Stand. Mag. 2021, 5, 48-54. [CrossRef] 
28. Arbib, J.; Seba, T. Rethinking Transportation 2020-2030-The Disruption of Transportation and the Collapse of the InternalCombustion Vehicle and Oil Industries. 2017. Available online: https://static1.squarespace.com/static/585c3439be65942f022 bbf9b/t/591a2e4be6f2e1c13df930c5/1509063152647/RethinkX\%2bReport_051517.pdf (accessed on 3 May 2021).

29. 5GAmericas. 5G Services and Use Cases. 2019. Available online: https://www.5gamericas.org/5g-services-use-cases / (accessed on 3 May 2021).

30. Wang, J.; Zhong, H.; Xia, Q.; Kang, C. Optimal Planning Strategy for Distributed Energy Resources Considering Structural Transmission Cost Allocation. IEEE Trans. Smart Grid 2018, 9, 5236-5248. [CrossRef]

31. Song, Y.; Lin, J.; Tang, M.; Dong, S. An Internet of Energy Things Based on Wireless LPWAN. Engineering 2017, 3, 460-466. [CrossRef]

32. Accenture Strategy-The Impact of 5G on the European Economy. 2021. Available online: https://www.accenture.com/ _acnmedia/PDF-144/Accenture-5G-WP-EU-Feb26.pdf (accessed on 3 May 2021).

33. Ma, K.; Liu, X.; Liu, Z.; Chen, C.; Liang, H.; Guan, X. Cooperative Relaying Strategies for Smart Grid Communications: Bargaining Models and Solutions. IEEE Internet Things J. 2017, 4, 2315-2325. [CrossRef]

34. Fadel, E.; Gungor, V.; Nassef, L.; Akkari, N.; Maik, M.A.; Almasri, S.; Akyildiz, I.F. A Survey on Wireless Sensor Networks for Smart Grid. Comput. Commun. 2015, 71, 22-33. [CrossRef]

35. S, S.R.; Dragičević, T.; Siano, P.; Prabaharan, S.S. Future Generation 5G Wireless Networks for Smart Grid: A Comprehensive Review. Energies 2019, 12, 2140. [CrossRef]

36. Jewkes, S.; Steitz, C. Power to the Drones: Utilities Place Bets on Robots. 2018. Available online: https://www.reuters.com/ article/ctech-us-utilities-drones-europe-analysi-idCAKBN1K60TS-OCATC (accessed on 3 May 2021).

37. Porter, J. Go Read This Analysis of What the iPad Pro's LIDAR Sensor Is Capable of. 2020. Available online: https://www. theverge.com/2020/4/16/21223626/ipad-pro-halide-camera-lidar-sensor-augmented-reality-scanning (accessed on 3 May 2021).

38. Infotech-Utilities in Europe Accelerate Digital Transformation. 2020. Available online: https://infotechlead.com/cio/utilitiesin-europe-acceleratedigital-transformation-62370 (accessed on 3 May 2021).

39. Brown, G. Private 5G Mobile Networks for Industrial IoT—Qualcomm. 2019. Available online: https://www.qualcomm.com/ media/documents/files/private-5g-networks-for-industrial-iot.pdf (accessed on 3 May 2021).

40. Trabish, H.K. Demand Response Failed California 20 Years Ago; the State's Recent Outages May Have Redeemed It. 2020. Available online: https:/ / www.utilitydive.com/news/demand-response-failed-california-20-years-ago-the-states-recent-outages / 584878 / (accessed on 3 May 2021).

41. Person. 5G-Driver of the Next Generation Smart Grid. 2019. Available online: https://www.engerati.com/transmissiondistribution/5g-driver-of-the-next-generation-smart-grid/ (accessed on 3 May 2021).

42. Safiliou-Rothschild, C. Are Older People Responsible for High Healthcare Costs? CESifo Forum 2009, 10, 57-64.

43. By 2020 Europe May Be Short of Two Million Healthcare Workers. 2010. Available online: https://healthcare-in-europe.com/en/ news / by-2020-europe-may-be-short-of-two-million-healthcare-workers.html (accessed on 3 May 2021).

44. Michel, J.P.; Ecarnot, F. The shortage of skilled workers in Europe: Its impact on geriatric medicine. Eur. Geriatr. Med. 2020, 11, 345-347. [CrossRef]

45. World Health Organization—Global Strategy on Human Resources for Health: Workforce 2030—Data and Statistics. 2021. Available online: https:/ / www.euro.who.int/en/health-topics/Health-systems/health-workforce/data-and-statistics (accessed on 3 May 2021).

46. Li, D. 5G and intelligence medicine-How the next generation of wireless technology will reconstruct healthcare? Precis. Clin. Med. 2019, 2, 205-208. [CrossRef]

47. Ericsson 5G Healthcare-Understanding the Opportunities for Operators in Healthcare. 2019. Available online: https://www. ericsson.com/en/networks/trending/insights-and-reports/5g-healthcare (accessed on 3 May 2021).

48. Campbell, D. New Report Reveals Alarming Shortage of Country Doctors. 2019. Available online: https://www.theguardian. com/society/2019/oct/13/nhs-consultant-shortage-rural-coastal-areas (accessed on 3 May 2021).

49. European Commission-Inequalities in Access to Healthcare-A Study of National Policies. 2018. Available online: https: / / op.europa.eu/en/publication-detail/- / publication/aff4d623-e7c2-11e8-b690-01aa75ed71a1 (accessed on 3 May 2021).

50. AT\&T. 5G and Healthcare: The Dawn of 5G Technology Is Here. 2019. Available online: https://www.business.att.com/content/ dam/attbusiness/briefs/5g-healthcare-ebook-brief.pdf (accessed on 3 May 2021).

51. Tan, S.S.; Bakker, J.; Hoogendoorn, M.E.; Kapila, A.; Martin, J.; Pezzi, A.; Pittoni, G.; Spronk, P.E.; Welte, R.; Hakkaart-van Roijen, L. Direct Cost Analysis of Intensive Care Unit Stay in Four European Countries: Applying a Standardized Costing Methodology. Value Health 2012. [CrossRef]

52. Lilly, C.M.; Cody, S.; Zhao, H.; Landry, K.; Baker, S.P.; McIlwaine, J.; Chandler, M.W.; Irwin, R.S. Hospital Mortality, Length of Stay, and Preventable Complications Among Critically Ill Patients Before and After Tele-ICU Reengineering of Critical Care Processes. JAMA 2011, 305, 2175-2183. [CrossRef]

53. Smart, N.A.; Titus, T.T. Outcomes of Early versus Late Nephrology Referral in Chronic Kidney Disease: A Systematic Review. Am. J. Med. 2011, 124, 1073-1080.e2. [CrossRef] [PubMed]

54. AT\&T-5 Ways 5G Will Transform Healthcare. Available online: https://www.business.att.com/learn/updates/how-5g-willtransform-the-healthcare-industry.html (accessed on 3 May 2021). 
55. Scully, P. Industrial IoT Platforms for Manufacturing 2019-2024 Report-IoT Analytics. 2019. Available online: https://iotanalytics.com/product/iiot-platforms-manufacturing-market-report-2019-2024/ (accessed on 3 May 2021).

56. Francesca. Addressing the Manufacturing Skills Gap. 2020. Available online: https://mpemagazine.co.uk/2020/05/19 /addressing-the-manufacturing-skills-gap/ (accessed on 3 May 2021).

57. Gold, S. The Perfect Storm for the Manufacturing Workforce. 2018. Available online: https://www.industryweek.com/ leadership/article/22025790/the-perfect-storm-for-the-manufacturing-workforce (accessed on 3 May 2021).

58. EuroStat-Accidents at Work Statistics. 2020. Available online: https://ec.europa.eu/eurostat/statistics-explained/index.php/ Accidents_at_work_statistics (accessed on 3 May 2021).

59. Wopata, M. Industry 4.0 Adoption 2020-Who Is Ahead?-IoT Analytics. 2020. Available online: https://iot-analytics.com/ industry-4-0-adoption-2020-who-is-ahead/ (accessed on 3 May 2021).

60. Essex, D. Ford Unlocks Potential Of 5G To Future-Proof Electric Vehicle Production. 2020. Available online: https: //media.ford.com/content/fordmedia/feu/gb/en/news/2020/06/25/ford-unlocks-potential-of-5g-to-future-proof-electricvehicle-pr.html (accessed on 3 May 2021).

61. International Federation of Robotics. 2021. Available online: https:/ /ifr.org/case-studies/collaborative-robots/stihl-opens-upnew (accessed on 3 May 2021).

62. Sprovieri, J. Capital Spending Report 2019: Manufacturers Continue to Invest in Technology. 2019. Available online: https://www. assemblymag.com/articles/95337-assembly-capital-spending-report-2019-manufacturers-continue-to-invest-in-technology (accessed on 3 May 2021).

63. Assembly Magazine-Lockheed Martin Embraces AR on the Factory Floor. 2019. Available online: https://www.assemblymag. com/articles/95163-lockheed-martin-embraces-ar-on-the-factory-floor (accessed on 3 May 2021).

64. Kapoor, R. Industrial AI at Bosch. 2019. Available online: https://bosch-connected-world.com/wp-content/uploads/BCW19 Breakout_Artificial_Intelligence_Rahul-Kapoor_Bosch.pdf (accessed on 3 May 2021).

65. Intel-How 5G Will Transform the Business of Media and Entertainment. 2018. Available online: https://newsroom.intel.com/ wp-content/uploads/sites/11/2018/10/ovum-intel-5g-ebook.pdf (accessed on 3 May 2021).

66. Gartner Research-Gartner Says By 2020, a Quarter Billion Connected Vehicles Will Enable New In-Vehicle Services and Automated Driving Capabilities. 2015. Available online: https://www.gartner.com/en/newsroom/press-releases/2015-0126-gartner-says-by-2020-a-quarter-billion-connected-vehicles-will-enable-new-in-vehicle-services-and-automated-drivingcapabilities (accessed on 3 May 2021).

67. Teece, D.J. 5G Mobile: Disrupting the Automotive Sector. 2017. Available online: https://www.qualcomm.com/media/ documents / files/5g-mobile-disrupting-the-automotive-sector.pdf (accessed on 3 May 2021).

68. Alibaba Cloud: 'City Brain' Lowers Traffic Congestion Rate by 15\% in Sichuan Province. Available online: https: / / equalocean. com/news / 2020082614640 (accessed on 3 May 2021).

69. Rodrigue, J.P.; Comtois, C.; Slack, B. The Geography of Transport Systems; Routledge: London, UK, 2016. [CrossRef]

70. Gross, M. A planet with two billion cars. Curr. Biol. 2016, 26, R307-R310. [CrossRef]

71. World Health Organization-Global Status Report on Road Safety 2018. 2018. Available online: https://www.who.int/ publications/i/item/9789241565684 (accessed on 3 May 2021).

72. Kim, J.; Moon, Y.; Suh, I. Smart Mobility Strategy in Korea on Sustainability, Safety and Efficiency Toward 2025. IEEE Intell. Transp. Syst. Mag. 2015, 7, 58-67. [CrossRef]

73. Anderson, J.M.; Nidhi, K.; Stanley, K.D.; Sorensen, P.; Samaras, C.; Oluwatola, O.A. Autonomous Vehicle Technology: A Guide for Policymakers; RAND Corporation: Santa Monica, CA, USA, 2016.

74. Litman, T. Autonomous Vehicle Implementation Predictions Implications for Transport Planning; Victoria Transport Policy Institute: Victoria, BC, Canada, 2018. Available online: https:/ / www.vtpi.org/avip.pdf (accessed on 3 May 2021).

75. 3GPP-Technical Specification Group Services and System Aspects; Enhancement of 3GPP Support for V2X Scenarios; Stage 1 (Release 16). 2019. Available online: https://portal.3gpp.org/desktopmodules/Specifications/SpecificationDetails.aspx?specificationId= 3180 (accessed on 3 May 2021).

76. Hussain, R.; Sherali, Z. Autonomous Cars: Research Results, Issues and Future Challenges. IEEE Commun. Surv. Tutor. 2018. [CrossRef]

77. IHS Markit-Autonomous Vehicle Sales to Surpass 33 Million Annually in 2040, Enabling New Autonomous Mobility in More Than $26 \%$ of New Car Sales. 2018. Available online: https:/ / ihsmarkit.com/research-analysis/autonomous-vehicle-sales-tosurpass-33-million-annually-in-2040-enabling-new-autonomous-mobility-in-more-than-26-percent-of-new-car-sales.html (accessed on 3 May 2021).

78. SAE International-Taxonomy and Definitions for Terms Related to On-Road Motor Vehicle Automated Driving Systems. 2014. Available online: http:/ /www.sae.org/ (accessed on 3 May 2021).

79. Ross, P.E. The Audi A8: The World's First Production Car to Achieve Level 3 Autonomy. IEEE Spectr. 2017. Available online: https:/ / spectrum.ieee.org/cars-that-think/transportation/self-driving/the-audi-a8-the-worlds-first-production-carto-achieve-level-3-autonomy (accessed on 3 May 2021).

80. Shahzad, K. Cloud Robotics and Autonomous Vehicles I IntechOpen. Available online: https://www.intechopen.com/books / autonomous-vehicle/cloud-robotics-and-autonomous-vehicles (accessed on 3 May 2021). 
81. Marletto, G. Who Will Drive the Transition to Self-Driving? A Socio-Technical Analysis of the Future Impact of Automated Vehicles. Technol. Forecast. Soc. Chang. 2019, 139, 221-234. [CrossRef]

82. Eykholt, K.; Evtimov, I.; Fernandes, E.; Li, B.; Rahmati, A.; Xiao, C.; Prakash, A.; Kohno, T.; Song, D. Robust Physical-World Attacks on Deep Learning Visual Classification. In Proceedings of the 2018 IEEE/CVF Conference on Computer Vision and Pattern Recognition, Salt Lake City, UT, USA, 18-23 June 2018; pp. 1625-1634. [CrossRef]

83. Brooks, R. Robotic cars won't understand us, and we won't cut them much slack. IEEE Spectr. 2017, 54, 34-51. [CrossRef]

84. Fairley, P. Self-driving cars have a bicycle problem [News]. IEEE Spectr. 2017, 54, 12-13. [CrossRef]

85. C-ITS Vehicle to Infrastructure Services: How C-V2X Technology Completely Changes the Cost Equation for Road Operators. Available online: https://5gaa.org/news/5gaa-releases-white-paper-on-the-benefits-of-using-existing-cellular-networks-forthe-delivery-of-c-its / (accessed on 3 May 2021).

86. Americas, G. Cellular V2X Communications Towards 5G. 2019. Available online: https://www.5gamericas.org/cellular-v2xcommunications-towards-5g/ (accessed on 3 May 2021).

87. 5G-Americas. 5G: The Future of IoT. 2020. Available online: https://www.5gamericas.org/5g-the-future-of-iot/ (accessed on 3 May 2021).

88. Gohar, A.; Lee, S. A cost efficient multi remote driver selection for remote operated vehicles. Comput. Netw. 2020, 168, 107029. [CrossRef]

89. Balasubramaniam, A.; Paul, A.; Hong, W.-H.; Seo, H.; Kim, J.H. Comparative Analysis of Intelligent Transportation Systems for Sustainable Environment in Smart Cities. Sustainability 2017, 9, 1120. [CrossRef]

90. Division, U.E.T. Intelligent transport systems (ITS) for sustainable mobility. In United Nations Digital Library; UN: New York, NY, USA, 2012.

91. World Economic Forum White Paper Digital Transformation of Industries; In collaboration with Accenture. World Economic Forum: Cologny, Switzerland, 2016; p. 29. Available online: https://reports.weforum.org/digital-transformation/wp-content/blogs.dir/ 94/mp/files/pages/files/digital-enterprise-narrative-final-january-2016.pdf (accessed on 3 May 2021).

92. Fischer, A. My Car, My Hero: What the Connected Vehicle Will Be Capable of Doing on the Streets of the Future. 2017. Available online: https:/ / www.automotiveworld.com/news-releases/car-hero-connected-vehicle-will-capable-streets-future/ (accessed on 3 May 2021).

93. ITSA. Transportation Safety Spectrum V2X Letter to Senate Communications Technology Innovation and the Internet Subcommittee. 2020. Available online: https:/ /itsa.org/wp-content/uploads/2020/07/Transportation-Safety-Spectrum-V2X-Letter-toSenate-Communications-Technology-Innovation-and-the-Internet-Subcommittee-072220.pdf (accessed on 3 May 2021).

94. Knobloch, F.; Braunschweig, N. A Traffic-Aware Moving Light System Featuring Optimal Energy Efficiency. IEEE Sens. J. 2017, 17, 7731-7740. [CrossRef]

95. Shell, C. Intelligent Traffic Systems and V2X Communication-If Cars Could Talk. 2019. Available online: https://www. cleantech.com/intelligent-traffic-systems-and-v2x-communication-if-cars-could-talk/ (accessed on 3 May 2021).

96. Smith, J. European Mobility Week 2016: Sustainable Transport Is an Investment for Europe. 2019. Available online: https: / / ec.europa.eu/transport/media/news/2016-09-16-european-mobility-week_en (accessed on 3 May 2021).

97. Martin, W. Traffic Delays Will Cost the UK Economy More Than $£ 300$ Billion by 2030. 2017. Available online: https://www. businessinsider.com/cebr-study-on-uk-congestion-and-economic-costs-2017-2 (accessed on 3 May 2021).

98. Anonymous. Cooperative, Connected and Automated Mobility (CCAM). 2020. Available online: https://ec.europa.eu/ transport/themes/its/c-its_en (accessed on 3 May 2021).

99. Smart Parking Tech Might Be Paying Off in U.S. Cities. Available online: https://www.govtech.com/transportation/SmartParking-Tech-US-Cities.html (accessed on 3 May 2021).

100. West, D.M. Achieving Sustainability in a 5G World; Centre for Technology Innovation at Brookings: Washington, DC, USA, 2016. Available online: https://www.brookings.edu/wp-content/uploads/2016/11/gs_20161201_smartcities_paper.pdf (accessed on 3 May 2021).

101. Detroit's Smart Intersections, Which Can Update Like Smartphones, Could Save Lives. Available online: https:/ /www.govtech. $\mathrm{com} / \mathrm{fs} /$ Detroits-Smart-Intersections-Which-Can-Update-Like-Smartphones-Could-Save-Lives.html (accessed on 3 May 2021).

102. Kim, K.; Kim, J.S.; Jeong, S.; Park, J.H.; Kim, H.K. Cybersecurity for autonomous vehicles: Review of attacks and defense. Comput. Secur. 2021, 103, 102150. [CrossRef]

103. Munir, A. Safety Assessment and Design of Dependable Cybercars: For today and the future. IEEE Consum. Electron. Mag. 2017, 6, 69-77. [CrossRef]

104. Yan, C.; Xu, W.; Liu, J. Can You Trust Autonomous Vehicles: Contactless Attacks against Sensors of Self-Driving Vehicle (DEF CON 24). 2016. Available online: https://infocondb.org/con/def-con/def-con-24/can-you-trust-autonomous-vehiclescontactless-attacks-against-sensors-of-self-driving-vehicle (accessed on 3 May 2021).

105. Ren, K.; Wang, Q.; Wang, C.; Qin, Z.; Lin, X. The Security of Autonomous Driving: Threats, Defenses, and Future Directions. Proc. IEEE 2020, 108, 357-372. [CrossRef]

106. Solon, O. Team of Hackers Take Remote Control of Tesla Model S from 12 Miles Away. 2016. Available online: https: / / www.theguardian.com/technology/2016/sep/20/tesla-model-s-chinese-hack-remote-control-brakes (accessed on 3 May 2021). 
107. Greenberg, A. The Jeep Hackers Are Back to Prove Car Hacking Can Get Much Worse. 2016. Available online: https: //www.wired.com/2016/08/jeep-hackers-return-high-speed-steering-acceleration-hacks/ (accessed on 3 May 2021).

108. BMW Cars Found to Contain More Than a Dozen Flaws. 2018. Available online: https://www.bbc.com/news/technology-4422 4794 (accessed on 3 May 2021).

109. Ali, Q.E.; Ahmad, N.; Malik, A.H.; Ali, G.; Rehman, W.U. Issues, Challenges, and Research Opportunities in Intelligent Transport System for Security and Privacy. Appl. Sci. 2018, 8, 1964. [CrossRef]

110. NHTSA. 2016 Fatal Motor Vehicle Crashes. 2018. Available online: https://www.nhtsa.gov/press-releases/usdot-releases-2016 -fatal-traffic-crash-data (accessed on 3 May 2021).

111. Ranney, T.A.; Garrott, W.R.; Goodman, M.J. Nhtsa Driver Distraction Research: Past, Present, and Future. 2001. Available online: https:/ / www.sae.org/publications/technical-papers/content/2001-06-0177/ (accessed on 3 May 2021).

112. Chung, J.j.; Kim, H.J. An Automobile Environment Detection System Based on Deep Neural Network and its Implementation Using IoT-Enabled In-Vehicle Air Quality Sensors. Sustainability 2020, 12, 2475. [CrossRef]

113. Khan, M.Q.; Lee, S. A Comprehensive Survey of Driving Monitoring and Assistance Systems. Sensors 2019, 19, 2574. [CrossRef]

114. Hahn, D.; Munir, A.; Behzadan, V. Security and Privacy Issues in Intelligent Transportation Systems: Classification and Challenges. IEEE Intell. Transp. Syst. Mag. 2021, 13, 181-196. [CrossRef]

115. Gogoll, J.; Müller, J.F. Autonomous Cars: In Favor of a Mandatory Ethics Setting. Sci. Eng. Ethics 2016, 23, 681-700. [CrossRef]

116. Johnsen, A.; Strand, N.; Andersson, J.; Patten, C.; Kraetsch, C.; Takman, J. Literature Review on the Acceptance and Road Safety, Ethical, Legal, Social and Economic Implications of Automated Vehicles. Deliverable 2.1 from the EU-H2020-Project BRAVE_BRidging the Gaps for the Adoption of Automated VEhicles. 2018. Available online: https://www.ifes.fau.de/files/20 19/02/Mat-2-2018-BRAVE-D2.1-Literature-review-FINAL.pdf (accessed on 3 May 2021).

117. Privacy by Design Aspects of C-V2X. 2020. Available online: https://5gaa.org/news/privacy-by-design-aspects-of-c-v2x/ (accessed on 3 May 2021).

118. Ackerman, E. Fatal Tesla Self-Driving Car Crash Reminds Us That Robots Aren't Perfect. 2016. Available online: https://spectrum. ieee.org/cars-that-think/transportation/self-driving/fatal-tesla-autopilot-crash-reminds-us-that-robots-arent-perfect (accessed on 3 May 2021).

119. Bergen, M.; Newcomer, E. Uber Halts Autonomous Car Tests after Fatal Crash in Arizona. 2018. Available online: https: / / www.bloomberg.com/news/articles/2018-03-19/uber-autonomous-car-involved-in-fatal-crash-in-arizona (accessed on 3 May 2021).

120. Viereckl, R.; Ahlemann, D.; Koster, A.; Jursch, S. Racing Ahead with Autonomous Cars and Digital Innovation. Auto Tech Rev. 2015, 4, 18-23. [CrossRef]

121. Awad, E.; Dsouza, S.; Kim, R.; Schulz, J.; Henrich, J.; Shariff, A.; Bonnefon, J.F.; Rahwan, I. The Moral Machine experiment. Nature 2018, 563, 59-64. [CrossRef]

122. Penmetsa, P.; Adanu, E.K.; Wood, D.; Wang, T.; Jones, S.L. Perceptions and expectations of autonomous vehicles-A snapshot of vulnerable road user opinion. Technol. Forecast. Soc. Chang. 2019, 143, 9-13. [CrossRef]

123. Goodall, N.J. Machine Ethics and Automated Vehicles. Road Veh. Autom. 2014, 93-102. [CrossRef]

124. Santoni de Sio, F. Killing by Autonomous Vehicles and the Legal Doctrine of Necessity. Ethical Theory Moral Pract. 2017, 20, 411-429. [CrossRef]

125. Contissa, G.; Lagioia, F.; Sartor, G. The Ethical Knob: Ethically-customisable automated vehicles and the law. Artif. Intell. Law 2017, 25, 365-378. [CrossRef]

126. Lin, P. The Ethics of Autonomous Cars. 2013. Available online: https://www.theatlantic.com/technology/archive/2013/10/theethics-of-autonomous-cars/280360/ (accessed on 3 May 2021).

127. Nyholm, S. The ethics of crashes with self-driving cars: A roadmap, I. Philos. Compass 2018, 13, e12507. [CrossRef]

128. Peters, E. Can a Self-Driving Car Glitch Threaten Passenger Safety? 2020. Available online: https://www.govtech.com/fs/Cana-Self-Driving-Car-Glitch-Threaten-Passenger-Safety.html (accessed on 3 May 2021).

129. Fountain, H. A Slow Ride Toward the Future of Public Transportation. 2016. Available online: https://www.nytimes.com/2016 /11/08/science/ finland-public-transportation-driverless-bus.html (accessed on 3 May 2021).

130. Lari, A.; Douma, F.; Onyiah, I. Self-Driving Vehicles and Policy Implications: Current Status of Autonomous Vehicle Development and Minnesota Policy Implications. 2015. Available online: https:/ / conservancy.umn.edu/handle/11299/172958 (accessed on 3 May 2021).

131. Tracy, S. Autonomous Vehicles Will Replace Taxi Drivers, But That's Just the Beginning.2017. Available online: https://www. huffpost.com/entry/autonomous-vehicles-will-_b_7556660 (accessed on 3 May 2021).

132. Engelbert, C. Driverless Cars and Trucks Don't Mean Mass Unemployment-They Mean New Kinds of Jobs. 2017. Available online: https:/ / qz.com/1041603/driverless-cars-and-trucks-dont-mean-mass-unemployment-they-mean-new-kinds-of-jobs / (accessed on 3 May 2021).

133. Kemp, J. Driverless Cars Will Take the Fun Out of Driving. 2018. Available online: http://www.drivewrite.co.uk/driverlesscars-will-take-fun-driving/ (accessed on 3 May 2021).

134. Ericsson. The Industry Impact of 5G. 2018. Available online: http://www.astrid-online.it/static/upload/eric/ericsson_reportbnew-18000486-rev-a-uen.pdf (accessed on 3 May 2021). 
135. Tiffany, K. Something in the Air. 2020. Available online: https://www.theatlantic.com/technology/archive/2020/05/great-5gconspiracy/611317/ (accessed on 3 May 2021).

136. Reichert, C. 5G Coronavirus Conspiracy Theory Leads to 77 Mobile Towers Burned in UK, Report Says. 2020. Available online: https: / www.cnet.com/health/5g-coronavirus-conspiracy-theory-sees-77-mobile-towers-burned-report-says / (accessed on 3 May 2021).

137. Forum, W.E. World Economic Forum White Paper: The Impact of 5G: Creating New Value across Industries and Society. 2020. Available online: https://www.weforum.org/whitepapers/the-impact-of-5g-creating-new-value-across-industries-and-society (accessed on 3 May 2021). 